\title{
Cuidando de Quem Ensina: dificuldades e cuidados destinados aos professores de uma escola pública
}

\author{
Taking Care of the Teachers: difficulties and cares given to the teachers of public school
}

Cuidando de Quién Enseña: dificultades y cuidados destinados a los maestros de una escuela pública

Recebido: 19/03/2014

Aprovado: 05/08/2014

\section{Alice Faria Ferreira ${ }^{1}$ Laís Cristina Souza ${ }^{2}$ Helena de Ornellas Sivieri-Pereira ${ }^{3}$}

Este artigo tem o objetivo de relatar a experiência de estágio em uma escola pública da cidade de Uberaba/MG, que teve como proposta contribuir para o autoconhecimento, identidade docente e promoção da saúde da equipe, além de promover um melhor desenvolvimento de suas atividades profissionais e melhoria no processo educacional. Foram realizados onze encontros, entre reuniões, grupos com os professores, observações e devolutiva, ao longo de um semestre. Os temas discutidos abordavam as dificuldades do trabalho docente, os outros "eus" presentes na vida dos profissionais, a dinâmica de funcionamento de uma sala de aula, as dificuldades da equipe e a possibilidade de construção e transformação do ambiente escolar e da comunidade. Foi possível trabalhar a capacidade dos vários "Eus" que uma única pessoa pode vivenciar, permitindo aos participantes falarem de si, cuidarem de si e muitas vezes enxergarem a si mesmo. Foram enfrentadas dificuldades, mas ficou clara a necessidade de continuidade do trabalho na escola.

Descritores: Psicologia educacional; Saúde escolar; Esgotamento profissional; Autoimagem.

This paper aims to report the experience of the internship in a public school in Uberaba, Minas Gerais, Brazil. The internship intended to contribute to the self-knowledge and health promotion, moreover to promote a better development of teacher's professional activities and improve the educational process. There were eleven meetings during a semester, some with the teachers, other only observing and also some only with the internship personnel. The discussed themes approached the difficulties in working as a teacher, the other "selves" present in the professional lives of the teacher, the dynamic of the classroom, the difficulties of the team and the possibilities of the construction and transformation of the school environment and also the changes in the community. It was possible to work with the ability of the many "selves" that one only person could experience which allowed the participants to talk about themselves, take care of themselves and also see themselves. The internship group has faced many difficulties during the project, but the necessity of keeping the project is very clear.

Descriptors: Educational psychology; Health scholar; Burnout professional; Self concept.

Este artículo tiene como objetivo informar la experiencia de pasantía en una escuela pública en la ciudad de Uberaba, Minas Gerais. Brasil. La propuesta fue contribuir para el autoconocimiento, la identidad docente y promoción de la salud, y además de promover un mejor desarrollo de sus actividades profesionales y la mejora del proceso educativo. Se realizaron once encuentros entre reuniones, grupos con los maestros, observaciones y sesión de retroalimentación a lo largo del semestre. Los temas tratados abordaron las dificultades de la enseñanza, los otros "yo" en la vida actual de los profesionales, la dinámica de funcionamiento de un salón de clases, las dificultades del equipo y la capacidad de construir y transformar el ambiente de la escuela y la comunidad. Fue posible trabajar la capacidad de los diferentes "yos " que una sola persona puede experimentar, permitiendo a los participantes hablaren de sí mismos, cuidar de sí mismos y, a veces mirarse a sí mismos. Se encontraron dificultades, pero había una clara necesidad de continuar el trabajo en la escuela.

Descriptores: Psicología educacional; Salud escolar; Agotamiento Professional; Autoimagen.

\footnotetext{
${ }^{1}$ Acadêmica do Curso de Graduação em Psicologia da Universidade Federal do Triângulo Mineiro - UFTM. alicefaria@live.com

${ }^{2}$ Acadêmica do Curso de Graduação em Psicologia da UFTM. laiscristina.souza@hotmail.com

${ }^{3}$ Psicóloga. Mestre em Psicologia Escolar. Doutora em Psicologia. Professora do Mestrado em Educação e do Departamento de Psicologia da UFTM. helena.sivieri@gmail.com
} 


\section{INTRODUÇÃO}

trabalho de docência atualmente no

O Brasil tem esbarrado em situações de violência, descaso, insegurança e descrença com relação à educação. Pode-se dizer que professores têm direcionado seu discurso profissional, possibilitando aos jovens reconhecerem o verdadeiro sentido dos valores morais, respeito, direitos e deveres de um cidadão. Dessa forma, entende-se que para o papel da docência na atualidade é exigido um maior entendimento sobre a situação da sociedade, pois, é por meio das experiências vividas que jovens passam a compreender e dar sentindo as regras, tornando possível até mesmo uma resolução pacífica de conflitos ${ }^{1}$.

Dessa forma, as demandas que desgastam, desmotivam e até comprometem o trabalho do professor são inúmeras e o foco de cuidado raramente é direcionado ao papel daquele que está na linha de frente e geralmente sofre as maiores consequências. Vivem situações de salários baixos, perspectiva nula de melhoria na carreira, carga horária excessiva e sem reconhecimento da sua importância, além de serem expostos a condições de violência. Sendo assim, sabe-se que o medo e o esgotamento emocional resultam em falta de compromisso e descaso com as atividades que deveriam ser cumpridas, imperando desta forma, uma educação de má qualidade ${ }^{2}$.

O profissional da psicologia uniu-se, então, ao cenário escolar para que, juntamente com toda a equipe, pudesse entender discutir, julgar e levantar hipóteses sobre dificuldades da ordem institucional de educação. 0 trabalho do psicólogo no contexto escolar justifica-se, principalmente, a partir do pressuposto de que no exercício profissional da atividade docente vários fatores estressores psicossociais, alguns relacionados à natureza da função outros relacionados ao contexto institucional e social, influenciam na vida dos docentes podendo levar a adoecimentos ${ }^{3}$.

"A especificidade do que se denomina Psicologia Escolar em relação a outras áreas 320 ou ramos da Psicologia, tal como estão constituídas hoje, está dada pela conjunção de dois elementos: em primeiro lugar, pelo seu objetivo, sendo esse a contribuição para a otimização dos processos educativos, que acontecem na instituição escolar entendidos de forma ampla e também complexa pelos múltiplos fatores que neles intervêm (não apenas aqueles de ordem pedagógica, mas também de ordem subjetiva, relacional e organizacional); e, em segundo lugar, pelo lócus de atuação constituído pelas diferentes instâncias do sistema educativo, em especial a instituição escolar" 4 .

0 compromisso firmado entre a psicologia e a educação brasileira se estabelece através das possíveis mudanças a que o contexto escolar está sujeito. A participação consciente do psicólogo na promoção e efetivação das transformações demanda, além do compromisso profissional, a participação ativa e principalmente criativa, a fim de organizar estratégias e potencializar o trabalho a ser realizado na instituição $0^{5}$.

Considerando que o trabalho do psicólogo é múltiplo no contexto escolar, ou seja, várias abordagens teóricas podem sustentar ações neste ambiente, pode-se dizer que é favorável uma melhor articulação dos conhecimentos e processos específicos da profissão, para que haja uma articulação positiva frente às relações entre aprendizagem e desenvolvimento existente nesse contexto ${ }^{6}$.

Isto posto, fica claro que o psicólogo escolar precisa criar um espaço na instituição para escutar as demandas e refletir maneiras de lidar com situações rotineiras, elaborando formas de reflexão com os sujeitos, a fim de trabalhar relações e paradigmas $^{7}$. 0 profissional tem por principais tarefas: "aplicar conhecimentos psicológicos na escola, concernentes ao processo ensino-aprendizagem, em análises e intervenções psicopedagógicas; referentes ao desenvolvimento humano, às relações interpessoais e à integração famíliacomunidade-escola, para promover 0 desenvolvimento integral do ser; analisar as

REFACS(online)2014;2(3):319-327 
relações entre os diversos segmentos do sistema de ensino e sua repercussão no processo de ensino para auxiliar na elaboração de procedimentos educacionais capazes de atender às necessidades individuais; prestar serviços diretos e indiretos aos agentes educacionais, como profissional autônomo, orientando programas de apoio administrativo e educacional; desenvolver estudos e analisar as relações homem-ambiente físico, material, social e cultural quanto ao processo ensinoaprendizagem e produtividade educacional; desenvolver programas visando a qualidade de vida e cuidados indispensáveis às atividades acadêmicas; implementar programas para desenvolver habilidades básicas para aquisição de conhecimento e o desenvolvimento humano" 8 .

A necessidade de psicólogos escolares, nas escolas, trabalhando com o docente, é evidenciada por alguns fatores relacionados à saúde do trabalhador. Esse que atualmente vivencia momentos de estresses que a princípio, no Brasil, parece estar associado aos baixos salários, à precariedade das condições de trabalho, às atribuições burocráticas desgastantes, ao elevado número de alunos por sala de aula, ao despreparo do professor diante das novas situações e emergências da época, às pressões exercidas pelos pais dos alunos e pela sociedade em geral, à violência instaurada nas escolas, entre outros elementos ${ }^{9}$.

Identifica-se como crescente 0 adoecimento de professores que enfrentam rotinas desgastantes e que promovem, além do adoecimento físico, o adoecimento psíquico, tornando ainda mais fundamental o trabalho do psicólogo nas escolas. "Considerando que todo o trabalho é constituído de cargas, o trabalho docente também tem: cargas físicas - exigências que têm materialidade externa e que se modificam na interação com o corpo (interação ambiental), e cargas psíquicas disposições psicológicas que adquirem materialidade no próprio corpo e se expressam por meio dele (reações emocionais), que influenciam direta e indiretamente na saúde e na vida dos professores. Para a compreensão da problemática das alterações da relação entre trabalho e a saúde de quem trabalha, tornase importante saber como o trabalho está organizado" 10.

Dessa forma, acredita-se que além de toda a atividade já proposta ao psicólogo escolar, o que ainda lhe cabe como função é a promoção e prevenção da saúde mental dos funcionários e principalmente do quadro de docência da instituição. 0 que pode se dizer sobre promoção e prevenção, é que estão atreladas à contribuição de reformulações pessoais e institucionais possíveis aos integrantes do contexto escolar. Ou seja, caminham no sentido de despertar transformações e proporcionar mudanças significativas em seu desenvolvimento. Sendo assim, o psicólogo trabalha no intuito de estimular crescimento e qualidade profissional sobre as concepções de avaliação, de aprendizagem e principalmente de desenvolvimento humano ${ }^{6}$.

Portanto, pode-se dizer que o trabalho desenvolvido na instituição e relatado neste artigo se justifica de duas formas. Num primeiro momento pela inclusão do acadêmico de psicologia na prática escolar e a possibilidade de aprendizado a partir dessa vivência, além de discussões teóricas sobre o tema. Mas, acima de tudo, sua importância maior está na possibilidade de identificar junto a educadores da rede de ensino formal e não formal, as principais questões relacionadas à sua experiência como profissionais e implementar junto a eles um trabalho de escuta e de intervenção psico-educacionalsocial, visando contribuir para o autoconhecimento, identidade docente e promoção da saúde da equipe promovendo um melhor desenvolvimento de suas atividades profissionais e melhoria no processo educacional. Assim, este artigo tem o objetivo de relatar a experiência de estágio em uma escola pública da cidade de Uberaba.

\section{MÉTODO}

Trata-se de um relato de experiência a partir de uma vivência realizada no estágio da REFACS(online)2014;2(3):319-327 
disciplina "Estágio Supervisionado em Educação e Saúde Coletiva I", do curso de Psicologia da Universidade Federal do Triângulo Mineiro - UFTM. O estágio foi realizado em uma escola estadual da cidade de Uberaba-MG, durante o primeiro semestre letivo de 2013. Após um comunicado com a diretora da instituição, com o fim de reestabelecer a proposta de atividade que já havia sido exercida antes.

A partir desse contato foi possível a primeira reunião com a equipe pedagógica, buscando esclarecer como e quando aconteceriam os encontros. A proposta tinha como foco a equipe pedagógica e as dificuldades enfrentadas no contexto escolar no cotidiano. 0 convite se estendeu a todos os funcionários.

Inicialmente a proposta estabelecida tinha como ideia um total de seis meses de atividade, das quais os encontros aconteceriam em uma sala privativa da própria instituição. Cada encontro realizado teria como duração uma hora e meia de atividade, sendo previamente estruturado de acordo com o encontro anterior. Dessa forma, apenas o primeiro encontro estava determinado. Os instrumentos e as propostas surgiriam de acordo com as demandas.

Para a realização dos encontros, foram levantados entre os educadores temas os quais eles sentissem necessidade de conversar e discutir, tais como: momentos de relaxamento, angústias pessoais, autoconhecimento e momentos para falarem sobre si, expectativas de futuro e dificuldades cotidianas.

A instituição em que o estágio foi realizado é uma escola estadual da cidade de Uberaba- MG que atende a um público de alunos que varia de $1^{\circ}$ ao 90 ano. Houve na escola a implementação do programa Mais Educação, do Governo Federal. O Programa Mais Educação foi instituído pela Portaria interministerial $17 / 2007$ e pelo Decreto Presidencial 7083/2010 e integra as ações do Plano de Desenvolvimento da educação PDE, como uma estratégia do governo Federal para induzir a ampliação da jornada escolar e a organização curricular, na perspectiva da educação integral. Trata-se do esforço para construção de uma ação intersetorial entre as políticas públicas educacionais e sociais, contribuindo, desse modo, tanto para a diminuição das desigualdades educacionais, quanto para a valorização da diversidade cultural brasileira.

Essa estratégia promove a ampliação de tempos, espaços, oportunidades educativas e o compartilhamento da tarefa de educar entre os profissionais da educação e de outras áreas, as famílias e diferentes atores sociais, sob a coordenação da escola com seus gestores, professores, estudantes e funcionários. Isso porque a Educação Integral, associada ao processo de escolarização, pressupõe a aprendizagem conectada à vida e ao universo de interesses e de possibilidades das crianças, adolescentes e jovens ${ }^{11}$.

Assim, em um turno essas crianças cumprem o horário curricular correspondente a sua idade e no turno seguinte (contra turno), realizam atividades extracurriculares, como por exemplo, nesta escola: aulas de reforço, atividades de leitura, e outras.

A escola conta com um espaço grande, com diversas salas divididas em dois blocos. Em um dos blocos acontecem as atividades do programa Mais Educação e em outro bloco as atividades regulares. Há duas quadras de esportes, alguns quiosques para jogos de tabuleiros, uma cozinha e um refeitório, secretaria, sala dos professores, sala de recursos (onde se encontra uma psicopedagoga que trabalha com crianças que apresentam diagnóstico de dificuldade de aprendizagem).

\section{RESULTADOS}

De acordo com a proposta e frente às dificuldades encontradas na efetivação do grupo, dos onze encontros totais, apenas quatro foram realizados com o grupo de professores, ao longo do semestre. A composição do grupo variava em cada encontro, sendo que apenas sete mulheres, mantinham-se frequentes. Sugeriu-se que os educadores, logo no primeiro encontro REFACS(online)2014;2(3):319-327 
levantassem temas que poderiam ser trabalhados nos encontros seguintes.

Dentre os temas propostos, encontrou-se: pedidos de relaxamento, angústias pessoais, autoconhecimento e momentos para falarem sobre si. Percebeuse que pedidos relacionados à angústia da vivencia escolar eram frequentes. Ao decorrer dos encontros, notou-se que muitas vezes os integrantes do grupo estavam estressados e vivenciam integralmente $\mathrm{o}$ papel de professor, fato que levou à decisão de explorar esses vieses, intercalando-o com os pedidos dos professores. Estavam presentes sete funcionários que compunham a equipe, quatro estagiários e a professora da UFTM responsável pelo estágio.

Além desses encontros de grupo, houve três reuniões com a equipe pedagógica. Realizou-se uma observação em sala a pedido dos participantes de um dos grupos realizados. Realizou-se uma visita ao espaço físico da escola; participou-se, também, de uma palestra que envolvia a confraternização de fim de semestre e de uma Gincana Cultural. E por fim, houve a devolutiva para o encerramento das atividades da escola, totalizando, portanto, 11 encontros.

Conforme a composição do grupo mudava, variava à forma de condução e entrosamento. Alguns encontros simbolizaram momentos profundos de introspecção e autorreflexão, permitindo uma intensa sensibilidade entre aqueles presentes.

0 primeiro contato se configurou como estabelecimentos de vínculos $\mathrm{e}$ contratos referentes à atividade proposta. Buscou-se enfatizar a importância do psicólogo nas instituições de ensino e na contribuição mútua no trabalho. Préestabeleceu-se ainda, os dias e horários dos encontros a partir do calendário escolar.

No encontro seguinte os professores resolviam questões administrativas. Sendo assim, impossibilitou-se a realização de qualquer uma das atividades elaboradas. A convite da supervisora, falou-se novamente sobre a proposta de estágio, na tentativa de estimular as professoras a pensar em como construir um grupo onde lutar por objetivos semelhantes de melhorias e trocas mútuas de experiências como foco.

0 próximo grupo aconteceu em apenas meia hora, na tentativa de não se perder o interesse e a dedicação que estavam sendo construídas. Estabeleceu-se o sentido do grupo e o que todos ofereceriam e pediriam para o grupo acontecer de forma plena para que todos sentissem confortáveis, configurando um encontro importante de troca. Ouviu-se falar em estresse, frustração, impotência e medo que deparam na atividade de docência, necessidade de solidariedade entre as pessoas, a capacidade manter um equilíbrio na vida, a vontade de voltar a ser feliz como professora, ter fé em Jesus e sobre como a escola, mesmo com suas barreiras e dificuldades, continuava ser seu remédio.

Em conversas com a diretora, esta levantou questões referentes às dificuldades da escola, sobre a conduta profissional dos professores e principalmente sobre o que poderá ser feito, afim de que melhorias possam ocorrer na escola. Ressaltou ainda, alguns pontos de maior dificuldade da escola que é a comunicação com professores e com as crianças.

$\mathrm{Na}$ semana posterior realizou-se segundo dia de atividades com o grupo de professores. Pensando em acolher aqueles professores que não tinham vindo aos encontros ainda, realizou-se um acolhimento dos mesmos e a proposta de criação do grupo foi novamente retomada. Pediu-se novamente que temas fossem definidos para os encontros seguintes. Os temas sugeridos foram: solução para angústias pessoais, indisciplina (dos alunos), motivação (dos professores), escutar/ouvir, alunos testam professores (desafiam), relaxamento. Alguns professores sugeriam também, atividades para realizar (dinâmicas), diziam que o fato de ouvir e conversar, já são momentos únicos e terapêuticos.

Conversou-se, ainda, sobre as dificuldades que elas presenciam como docentes, diziam que os alunos possuem necessidades que passam das dificuldades do aprendizado e sugeriram que ocorresse

REFACS(online)2014;2(3):319-327 
uma visita na escola em horário de aula e se realizasse uma observação em sala de aula. A partir desta conversa se realizou uma atividade de comunicação, na qual foi destacada a necessidade e as formas de se comunicar, já que muitas demonstraram surpresa por um relato específico de uma colega de profissão. Realizou-se uma dinâmica que tinha por objetivo reestabelecer diferentes formas de comunicação, visando, a passagem da mesma mensagem de diversas maneiras. Após esta atividade, expressaram a aprendizagem que tiveram da possibilidade de outros modos de se comunicar e pediu-se para que cada uma falasse uma palavra que descrevesse o grupo no momento. As palavras citadas foram: esperança, equipe, equilíbrio, motivação, fortaleza, entre outras.

Em outro horário, diferente ao que o grupo acontecia, foi executada a observação proposta pelos professores no grupo para que alguns fatos se tornassem mais concretos frente às discussões que estavam sendo encaminhadas. A observação aconteceu na segunda-feira seguinte, na sala do quarto ano que frequenta o turno vespertino. Depois de muito alvoroço, e a professora cobrando a lição, as crianças se aquietaram e sentaram, mas não por muito tempo. Apesar das queixas apresentadas pelas professoras do grupo, nenhuma dificuldade foi observada como preocupante apenas muita disputa entre eles. A turma, como um todo, apresentou-se de forma bastante curiosa e extrovertida, e principalmente com o desenvolvimento adequado.

No terceiro encontro com o grupo de professores foi discutida a observação da sala do quarto ano e se percebeu a flexibilidade exigida do professor durante a aula. Sendo pontuado que os alunos exigem muita atenção dos professores, e para que a turma realize as atividades educacionais esse pedido de atenção deve ser atendido pelo professor em praticamente totalidade.

Discutiu-se sobre a percepção de que os professores se envolviam com o trabalho de forma que algumas vezes se esqueciam dos outros "eus" que envolviam sua existência.
Os professores confirmaram que muitas vezes esqueciam-se deles próprios, contaram que sentiam falta de um lugar na escola onde pudessem conversar com os outros funcionários e consequentemente descansarem.

Pensando nas pontuações feitas e principalmente no sentimento de desvalorização que os professores relatavam, foi proposta uma dinâmica com o objetivo de facilitar a integração da equipe e a percepção de qualidades apontadas pelos companheiros de trabalho. Alguns professores emocionaram-se. A equipe estava unida e entrosada, vivenciando e envolvendo-se no momento. A realização da dinâmica foi um momento de grande descontração dos professores. No final da dinâmica as conversas foram direcionadas sobre a necessidade ser ator da própria vida, além disso, de como o grupo se fortalecia. Os professores mostraram-se satisfeitos com o trabalho realizado.

0 próximo encontro aconteceu em um dia diferente do habitual, todos foram convidados a assistir uma palestra da superintendência de ensino. Foi evidente a necessidade de estimular e motivar a equipe. Reconheceu-se que a palestra ofertada trouxe ânimo e uma descontração diferente ao grupo. Em seguida realizaram uma confraternização já combinada, que encerraria as atividades daquele semestre.

No encontro seguinte, já no semestre subsequente, aconteceu o módulo conjunto entre todos os professores da Escola. Como o combinado, antes do inicio das férias, nesse módulo daria continuidade ao grupo com os professores. Contudo, o horário do módulo estava estruturado pela coordenação da escola visando discutir assuntos pertinentes à escola. A coordenação pediu o horário para discutirem esses assuntos, achando conveniente cedeu-se o horário, e as acadêmicas foram convidadas a participar da reunião.

$\mathrm{Na}$ semana seguinte, as professoras estavam empenhadas em organizar uma gincana histórica naquela instituição, fato que havia deixado a escola um tanto agitada, porém alegre, comunicativa e acolhedora, 
mais que o normal. A reunião girou em torno das discussões a respeito dessa gincana, divisão das equipes, das atividades e das oficinas que serão oferecidas no dia do evento.

Ainda nesse encontro, o tempo cedido às atividades foi aproveitado buscando-se discutir sobre como foram esses dias sem a escola. Tentou-se ao máximo coordenar a atividade, contudo as professoras falaram ao mesmo instante sobre variados temas. A pergunta inicial foi: "Como foi ficar sem a escola durante 15 dias?". Ouviram-se respostas variadas: muitas disseram que foi bom demais; outras que queriam voltar logo, pois é uma ocupação para cabeça e ficar sem fazer nada e sem dinheiro é ruim; outra disse que aproveitou bastante os filhos. Nesse momento a diretora disse que esteve na escola durante as férias e que a escola sem criança é muito triste.

Outra questão levantada foi a respeito dos pontos positivos de se estar sem a escola. Surgiram questões relacionadas ao descanso, ao convívio familiar, ao lazer, aos relacionamentos amorosos, as diversões e descontrações, ao não cumprimento de horário, entre outras.

Quando perguntado por que estava sendo bom voltar às aulas, foram relatados aspectos relacionados ao café, que agora estava acontecendo todos os fins de tarde e que dessa forma, as professoras estavam voltando com mais energia e com mais união. Uma professora ressaltou que estava com saudade do clima de equipe que havia se formado e que por morar sozinha estava sentindo muita falta das professoras que agora faziam parte de sua rotina. Entendiam que esta maior união era decorrente das atividades desenvolvidas durante os encontros.

Aproveitando o tema que estava em discussão, foi proposta uma atividade com temas sobre equipe, grupo e aquilo que se desejava para o próximo. Pediu-se que escrevesse em um pedaço de papel algo que desejasse que a colega de equipe cumprisse. Em seguida recolheram-se os papéis com os nomes de cada uma. Foi então informado que cada uma cumpriria seu próprio desejo, configurando-se um feito que virou contra o feiticeiro.

Com relação ao último encontro, toda a programação para fechamento dos encontros teve que ser alterada. No dia combinado para o último encontro, a diretora necessitou reunir a equipe com urgência e não foi possível realizar o que se havia planejado. No entanto, concederam alguns minutos para se esclarecer alguns aspectos que ficaram visíveis no decorrer das atividades.

Foi ressaltada a importância do trabalho em equipe se agradece a delicadeza sentida em cada encontro. Foi dada ênfase ainda na maneira como a equipe se constituía frente às dificuldades e que apesar das diferenças e divergências é possível construir, estimular e auxiliar no crescimento e desenvolvimento de cada criança e adolescente que ali se encontra. Além disso, ressaltou-se a importância da coordenação da escola cumprir com as atividades propostas, visto a dificuldade vivenciada com as marcações de reuniões em horários que foram estipulados pela diretoria para a realização do grupo.

\section{DISCUSSÂO}

Não há ao certo quanto de participação exata havia em cada encontro, uma vez que, muitas educadoras não permaneciam até o fim, outras chegavam atrasadas e por se configurar em um grupo aberto, a quantidade era o que menos importava. Cada momento das atividades realizadas trouxe uma contextualização diferenciada, com emoções e falas divergentes, contudo caracterizou-se um grupo importante e de muitas trocas, vividas de maneira intensa e especial, para cada um de uma forma única.

Por se tratar da continuação de um estágio do curso de Psicologia, não houve grandes resistências da direção da escola para dar continuidade ao trabalho com outros estagiários, mas durante a execução do mesmo vários momentos com os professores foram prejudicados ou perdidos devido a ações pontuais da diretoria frente a necessidades da escola. Os professores se mostraram interessados no decorrer dos

REFACS(online)2014;2(3):319-327 
encontros, o que trazia grande experiência para todos, pois a cada grupo houve um aprendizado construído com os participantes, seja esse aprendizado pessoal ou profissional.

No trabalho realizado com os grupos, ficou evidente que aqueles encontros buscaram uma melhoria dos participantes do grupo. Foi dada ênfase ao fato de que não são professores o tempo todo e que o trabalho do psicólogo na escola estava relacionado, também, às questões pessoais deles, que influenciam na prática ocupacional e na qualidade de vida e ressaltando o que autores como Pigatto ${ }^{1}$ descreve sobre o cuidado em se focar no professor, uma vez que, quem "faz frente" as dificuldades encontradas na escola atualmente são os mesmos.

É importante criar ambientes de análise da prática, de partilha das contribuições e reflexão sobre como se pensa, decide, comunica e reage em sala de aula; criar ambientes, para o profissional trabalhar sobre si, seus medos, emoções, na qual, seja incentivado o desenvolvimento da pessoa e sua identidade ${ }^{12}$.

Como retratado por Pigatto $^{1}$ os professores relataram momentos de insegurança, violência e descaso durante suas atividades de docência, sentimentos vivenciados seja por contato com alunos, seja pela comunidade em que estão inseridas ou por questões relacionadas ao professor. Contudo, ressalta-se a necessidade de compreensão da comunidade e dos costumes em que os alunos estão inseridos. Evitando a culpabilização de crianças que muitas vezes os buscam como principais mediadores de conflitos internos e externos que vivenciam. Tornando o educador um ator social na comunidade e mostrando como a realidade se encontra próxima aos olhos, podendo ser evidenciada na escola estadual a qual o estágio foi realizado.

o paradigma de que psicólogos sempre realizam diagnósticos, muitas vezes, foi ressaltado pelos professores. Nesse sentido, eles buscavam e pediam medidas para serem tomadas com "alunosproblemas", mesmo com as explicações sobre possibilidades de outras conversas e a não existência de uma "receita de bolo". Reafirmando a visão e postura apontada por Andrada7, em que a perspectiva da atuação do psicólogo escolar foi muitas vezes atuar com alunos considerados problemas e desconsiderando as questões sociais.

Sivieri-Pereira ${ }^{13}$ ressalta que estudos a respeito da "função" do professor no processo educativo, mostram que os professores, durante muito tempo, foram colocados em segundo plano tanto no que se refere à produção do conhecimento sistematizado sobre a própria prática, quanto como personagens da dinâmica educativa. Buscava-se estabelecer o melhor método de ensino, independentemente da participação do professor em qualquer instância do processo.

Nóvoa14, avalia que "a crise de identidade dos professores, objeto de inúmeros debates ao longo dos últimos 20 anos, não é alheia a esta evolução que foi impondo uma separação entre o eu pessoal e o eu profissional". Esse fato contribuiu em grande medida para o processo de desprofissionalização dos docentes.

Os resultados deste trabalho desenvolvido junto aos professores mostra que os fatos descritos, como supostamente históricos, estão presentes até hoje, no dia a dia da prática docente dificultando um eficaz desenvolvimento do processo educativo. Grupos como o proposto por este trabalho busca minimizar a distância entre o encontro das dimensões pessoais, com as dimensões profissionais da carreira docente.

\section{CONCLUSÃO}

Tratando-se de um trabalho o qual deu continuidade ao estágio anterior, que investigou e criou abertura para a atuação dos estagiários nessa instituição, buscou-se cada vez mais o envolvimento dos professores tentando fazer com que eles se envolvessem com a possibilidade do cuidado de si, mesmo que no seu ambiente de trabalho.

Com vista aos objetivos do estágio, foi possível trabalhar a capacidade dos vários "Eus" que uma única pessoa pode vivenciar e 
que todos esses a compõe na formação de um Eu-identidade, permitindo aos participantes do grupo falarem de si, cuidarem de si e muitas vezes enxergarem a si mesmos de uma maneira diferente.

O grupo sempre estava disposto e interagindo entre si, tanto nos momentos de discussões de assuntos relevantes da administração da escola quanto em momentos da realização do grupo. Percebeuse que muitas vezes o fato de os professores exporem sentimentos e problemas já era tido como terapêutico para alguns deles.

Sugerem-se alguns pontos que podem nortear e dar continuidade ao grupo com docentes desenvolvido no período de estágio: conduzir o grupo de forma firme, sem deixar se levar pelas dispersões ocasionadas por assuntos desconexos com as atividades propostas; utilizar trabalhos voltados à reflexão e discussão, uma vez que, a escola não possibilita tempo de diálogos entre eles; utilização de dinâmicas com fundamentação, que ocasione momentos de descontração e ao mesmo tempo introspecção e troca; utilização de músicas, imagens, frases de impacto, pois aceleram o raciocínio e possibilitam sensibilidade ao grupo. Atividades que trabalhem o corpo também são importantes, contudo devem ser mais voltadas para relaxamento e autoconhecimento, sem exposição dos integrantes e, que, evitem a utilização de métodos que exijam a escrita e testes.

As dificuldades encontradas perante a equipe correspondiam ao desgaste natural do dia a dia a que cada uma enfrentava, e dessa maneira, o grupo muitas vezes não conseguia compreender o verdadeiro foco das discussões. Muitos encontros passaram a ser momento de descontração ou até mesmo de descanso. Assuntos que não estavam em pauta eram discutidos e soluções, que também não cabiam ao momento, eram decididas. Entretanto, apesar de toda essa bagagem não pertencer ao momento, pertencia de alguma maneira ao que o estágio se propunha. Essas profissionais conseguiram transformar esse grupo de acordo com a necessidade que ali estava presente, sendo então, um momento especial, vivido com intensidade, emoção e que ao final, representou um lugar comum que fez a diferença, de forma individual em suas vidas.

\section{REFERÊNCIAS}

1. Pigatto N. A docência e a violência no contexto atual. Ensaio: Avaliação Política e Pública em Educação 2010; 18(67):303-24.

2. Ecco I. Elementos do cotidiano escolar de um grupo de docentes: preocupações, dificuldades e medos. Perspectiva 2012; 36(136):17-28.

3. Carlotto MS, LS Palazzo. Síndrome de burnout e fatores associados: um estudo epidemiológico com professores. Cad. Saúde Pública. 2006; 22(5):1017-26. 4. Martinez AM. O que pode fazer o psicólogo na escola? Em Aberto 2010; 23(83):39-56.

5. Martinez AM. Psicologia Escolar e Educacional: compromissos com a educação brasileira. Revista Semestral da Associação Brasileira de Psicologia Escolar e Educacional (ABRAPEE) 2009; 13(1):16977.

6. Oliveira SBE, CMM Araújo. Psicologia escolar: cenários atuais. Estudos e Pesquisas em Psicologia 2009; 9(3):648-63.

7. Andrada EGC. Novos paradigmas na prática do psicólogo escolar. Psicologia: Reflexão e Crítica 2005;(18):196-199.

8. Brasil. Conselho Federal de Psicologia. Resolução no013/2007. Brasília, 2007.

9. Canova KR, JB Porto. O impacto dos valores organizacionais no estresse ocupacional: um estudo com professores de ensino médio. Revista de Administração Mackenzie 2010; (11):4-31.

10. Lemos JC. Cargas Psíquicas no trabalho e processos de saúde em professores universitários (2005). Tese de Doutorado, Centro Tecnológico, Universidade Federal de Santa Catarina, Florianópolis-SC.

11. Brasil. Programa Mais Educação. Passo a Passo. 2011 [Acesso em 20 de abril de 2013]. Disponível em: portal.mec.gov.br/index.php?option=com_docman\&ta sk=doc

12. Alarcão I. Escola Reflexiva e Nova Racionalidade. (2001). Porto Alegre: Artmed.

13. Sivieri-Pereira HO. O professor principiante e os espaços de interação entre as dimensões pessoais e profissionais da carreira docente. (2008). Tese de Doutorado, Faculdade de Filosofia, Ciências e Letras de Ribeirão Preto, Universidade de São Paulo Ribeirão Preto-SP.

14. Nóvoa A. Vidas de professores. (2000). Porto. Portugal: Porto Editora.

CONTRIBUIÇÕES
Todas as autoras participaram de todas as
etapas de confecção do artigo.

